\title{
REDES DE USUÁRIOS-CULTIVADORES DE CANNABIS \\ NO BRASIL \\ MÓBEIS MORAIS E RELAÇÕES SOCIAIS
}

\section{CANNABIS USERS-GROWERS NETWORKS IN BRAZIL MORAL MOBILES AND SOCIAL RELATIONS}

\author{
Marco Vinicius de Castro \\ Universidade Federal de Juiz de Fora, Instituto de Ciências Humanas, Programa de Pós-Graduação em Ciências \\ Sociais. Campus Universitário, Rua José Lourenço Kelmer, s/n - São Pedro, 36036-900 Juiz de Fora - MG, Brasil. \\ E-mail: marco.castro@estudante.ufff.br | ORCID: https://orcid.org/0000-0003-0956-0613 \\ Paulo Cesar Pontes Fraga \\ Universidade Federal de Juiz de Fora, Instituto de Ciências Humanas, Departamento de Ciências Sociais e \\ Programa de Pós-Graduação em Ciências Sociais. Campus Universitário, Rua José Lourenço Kelmer, s/n - São \\ Pedro, 36036-900 Juiz de Fora - MG, Brasil. \\ E-mail: paulo.fraga@ufjf.edu.br | ORCID: https://orcid.org/0000-0001-9140-8586
}

Resumo: Este artigo parte do objetivo de estudar atores que cultivam a própria maconha para uso social-recreativo e, a partir disso, verificar a hipótese se suas ações, interações e associações suscitam efeitos morais. A partir de um trabalho de campo realizado em uma cidade do interior do Brasil e baseado no método etnográfico entre usuários que cultivam a própria maconha, observa-se que tais atores firmam uma vida moral de gênero único e configuram redes morais e relações sociais através de suas práticas. Logo, o plantio caseiro da própria maconha é considerado como uma fonte de relações morais sui generis, assim como um sentimento moral legítimo de libertação em relação às repressões formais e informais que esses atores sofrem.

Palavras-chave: moralidade, atores, cultivadores, cannabis.

\begin{abstract}
This article focuses on actors who grow their own marijuana for social-recreational use to assess whether their actions, interactions and associations give rise to moral effects. Based on ethnographic fieldwork carried out in a city in the interior of Brazil it is observed that such users who grow their own marijuana establish a single form of moral life and configure moral networks and social relationships through their practices. Therefore, the home planting of marijuana itself is considered as a source of sui generis moral relations, as well as a legitimate moral feeling of liberation from formal and informal repressions that these actors suffer.
\end{abstract}

Keywords: morality, actors, growers, marijuana.

\section{Introdução}

O consumo de drogas, substâncias psicoativas que alteram os estados de consciência, como a maconha, por exemplo, são práticas sociais comumente observadas em todas as sociedades. Essas práticas podem ser tanto recreativas e ocasionais quanto 
regulares e compulsivas, donde destas últimas podem culminar na rotulação de "viciado" ou "toxicômano", o que fez muitas convenções e tratados nacionais e internacionais classificarem certas substâncias como "entorpecentes" ou "drogas" ilícitas (Bergeron, 2012). Bergeron (2012) argumenta, todavia, que existe uma quantidade imensurável de substâncias psicoativas socializadas que atuam na consciência e, com o uso prolongado, podem também produzir o que é taxado como dependência, adição ou vício, como os casos do álcool, tabaco, remédios psicotrópicos controlados, ou mesmo o café, um dos psicoativos mais consumidos no mundo.

Essas distinções em relação a outras substâncias, das quais algumas o uso refinado é prezado, consoante Bergeron (2012), define clivagem entre drogas psicoativas socializadas, como o álcool, o tabaco, o café e remédios psicotrópicos em geral, e drogas psicoativas estigmatizadas, como a maconha, a cocaína, a heroína e o crack, onde estas últimas acabaram sendo criminalizadas e classificadas como ilícitas. Nessa perspectiva, considera-se que os usos de maconha, assim como de outras drogas lícitas ou ilícitas, podem configurar relações morais através de seus diferentes usos sociais, como nos casos dos usos medicinais, religiosos, científicos ou recreativos da maconha, por exemplo. Além disso, os usos de drogas psicoativas, tanto lícitas quanto ilícitas, podem suscitar diversos conflitos, controvérsias e polêmicas morais.

Ademais, existe no Brasil uma lacuna nos estudos de plantas consideradas ilícitas, tal como a maconha (Fraga, 2006, 2019). “Os estudos e as pesquisas sobre os usos de substâncias variadas que são caracterizadas pelo termo droga fazem parte já há décadas das reflexões das ciências sociais" (Alvarez, Fraga \& Campos, 2017, p. 1). Por este prisma, segundo olhar das ciências sociais, partimos do objetivo de construir uma reflexão sobre as ações, interações e associações de atores sociais envolvidos no cultivo caseiro de maconha para o próprio consumo, para verificar a hipótese de que esses atores configuram uma vida moral de gênero único. Assim, esse trabalho irá discutir duas questões-problema: Quais são motivações que servem como princípios dessa associação de atores que plantam a própria maconha? Quais relações sociais emergem dessa prática?

Feitos os preâmbulos, esse artigo está dividido em quatro partes. A primeira volta-se para esclarecer o enquadramento teórico e os conceitos-chave da pesquisa, tanto os que foram construídos no decorrer do estudo quanto os que foram mobilizados para análises. Posteriormente, serão feitas considerações metodológicas. Os dois próximos seguimentos trazem alguns resultados da pesquisa. A terceira seção discorrerá sobre as motivações desses atores e quais argumentos mobilizam para justificar a prática de plantar a própria cannabis. A quarta parte terá como enfoque as relações sociais configuradas por essa rede de atores. Por fim, este trabalho 
tentará esclarecer, a partir de observações e da ótica dos próprios atores, quais aspectos sociais emergem dessa prática e se suas ações, interações e associações em redes suscitam efeitos morais.

\section{Enquadramento teórico}

O conceito central utilizado para compreender as relações entre atores que plantam a própria maconha para uso social-recreativo é o de redes morais. Ele foi cunhado a partir das observações e interações de campo e da articulação de ideias de dois autores que são, sobretudo, controversos. Uma rede é pensada como um plano cartesiano em que o mapa das associações entre certos atores compõe um mundo social, e esses atores devem ser seguidos para descrever as suas marcas e trilhas produzidas nesse plano através do mapa de suas associações (Latour, 2012). Indivíduos que têm em comuns ideias, interesses, sentimentos ou ocupações que o resto da população não partilha com eles, podem se atrair pelas suas semelhanças, entrarem em relações e formar associações restritas no seio da sociedade, desprendendo-se dessas associações vidas morais específicas (Durkheim, 1983a).

Sendo assim, uma associação não é apenas uma autoridade moral que rege a vida de seus membros, mas também é uma fonte de vida sui generis, ou seja, uma moralidade, e o efeito moral que essa vida produz suscita um sentimento de solidariedade e empatia entre dois ou mais atores, formando associação moral entre eles (Durkheim, 1983a). Portanto, as redes morais são entendidas como conexões sociais que interligam atores que estão envolvidos em relações de similitudes morais, e dessas associações se desprendem vidas morais específicas e heterogêneas pelas sociedades afora (Castro, 2019). Nessa perspectiva, presume-se que estes atores que plantam a própria maconha se associam através de agregações configuradas no decurso de suas redes morais.

Como exemplo-limite de acusação de um crime, a lei tem a pretensão de universalidade, e a crítica feita a alguém que praticou um ato criminalizado está no horizonte da negatividade moral do ato (Werneck, 2013). Plantar a própria maconha no Brasil é considerado crime e tais atos invocam contra seu autor uma reação punitiva legal/moral (Magalhães, 1994), sejam essas reações formais ou informais (Becker, 2009). As reações formais no Brasil, ao tratar dos crimes e suas penalidades no que tange à produção de drogas ilícitas, sobretudo quando o crime se associa ao que é taxado como "tráfico de drogas", pode ser aplicável em alguns casos do plantio caseiro da própria maconha, pois a Lei 11.343, no Artigo 33, expõe que preparar, produzir, fabricar, ter em depósito, transportar, trazer consigo, guardar drogas sem autorização ou em desacordo com determinação legal ou regulamentar, pode 
ser penalizado em reclusão de cinco a quinze anos, além do pagamento de 500 a 1.500 dias-multa, enfatizando que as mesmas penas incorre quem semeia, cultiva ou faz a colheita de plantas que se constituam em matéria-prima para a preparação de drogas (Lei 11.343). Nos últimos anos, entretanto, há casos de juízes que concedem Habeas Corpus (HC) preventivos para pessoas que provocam a justiça nesse sentido visando poder usufruir, notadamente, dos benefícios medicinais da planta. Essas demandas que partem dos próprios pacientes de determinadas doenças visam, contraditoriamente, assegurar o direito à saúde utilizando os efeitos benéficos de uma planta cujo cultivo é proscrito.

Além disso, outra perspectiva analítica interessante referente ao poder de punir se encontra disperso no corpo social, protagonizado por instituições e grupos (Foucault, 2015), uma vez que se punem informalmente as pessoas, sugerindo que uma rede de poder punitiva informal está diluída pela sociedade afora. As categorias "drogado" e "maconheiro", quando mobilizadas por alguns atores para rotular outros, se configuram como atos de acusação moral e social que, no Brasil, se constitui como um dos rótulos de estigma mais acionados cotidianamente (Velho, 1981). O estigma perpassa por uma marca atribuída ao indivíduo como rótulo, diferencia-o dos demais e colocando-o numa situação de inabilitação de plena aceitação moral e social (Goffman, 1970). Nessa perspectiva, o estigma está relacionado ao ideário moral depreciativo inerente à carreira moral do estigmatizado. Atores estigmatizados podem aceitar os pontos de vistas dos ditos "normais", porém os ciclos de aceitação geralmente são conflituosos, pois pode acontecer tanto a rejeição do estigma quanto sua aceitação pelos estigmatizados (Goffman, 1970). Todas essas reações formais e informais citadas até aqui podem ser análogas quando se trata do plantio caseiro da própria maconha para o uso social no Brasil.

Ademais, ações reflexivas e interações surgem em contraposição às reações formais e informais sem perder suas determinações essenciais, e os pontos de vista dos atores que se encontram subjugados são emergências de suas subordinações experimentadas, uma vez que esses atores estabelecem novos valores (Misse, 2010). As pessoas "desviantes" que infringem regras formais e informais geralmente não aceitam a imposição de uma regra pela qual é julgado, pois podem compreender que os julgadores não são competentes ou legitimamente autorizados para fazê-lo (Becker, 2009). Os atores que plantam e usam a própria cannabis, quando se trata da ordem e sua antítese, agem de tal maneira porque acreditam dogmaticamente que podem contornar uma ordem para estabelecer uma "boa" ordem (Magalhães, 1994).

Nessa perspectiva, é importante chamar a atenção para a simetria entre os caracteres do que são considerados moral e imoral, principalmente sobre a mesma 
natureza de ambos (Durkheim, 1983b). Pode-se considerar que atos punidos como imorais não possuem nada em sua natureza que os diferencie dos atos considerados morais, pois se trata de atos da mesma espécie e, sendo assim, atos considerados imorais não produzem desagregação, mas uma reagregação, formando uma nova agregação moral em torno dos atos punidos como imorais, e uma acusação de imoralidade é resultado de um conflito, geralmente desigual e assimétrico, entre moralidades distintas (Magalhães, 1994). Aplicar o rótulo de "desviante" às pessoas que plantam maconha para o próprio consumo, nessa perspectiva de simetria, seria aceitar os valores das associações morais que formularam tal julgamento.

O conflito é uma das mais vívidas formas de interação, e ele pode tentar resolver dualismos divergentes e conseguir algum tipo de unidade, seja pacificamente ou através da aniquilação de uma das partes conflitantes, sendo este último o resultado violento do conflito (Simmel, 1983). A moral é o mundo do conflito dogmático, e quando o conflito coloca limites entre opressão e autonomia, ele estabelece agregações dos dois lados conflituosos (Magalhães, 1994). Por este prisma, os conflitos configurados pelos transgressores de regras, quando se trata da ordem social e sua antítese, suscitam conflitos políticos, considerando que a política está relacionada a qualquer ação intencional e estratégica que envolve o poder, seja este formal ou informal, tornando as altercações de certos atores com seus eventuais acusadores em um conflito político (Magalhães, 1994). Sendo assim, existe um aspecto político intrínseco no fenômeno de poder plantar a própria maconha para o uso próprio, e tal aspecto emerge dos conflitos que se estabelecem nessa relação entre imposição, sujeição e transgressão de regras formais e informais, e a partir dessas dissidências morais, esses atores enfrentam as coerções formais e informais que sofrem para configurar uma vida moral sui generis.

\section{Metodologia}

O método de estudo seguiu os critérios do desenho de uma pesquisa qualitativa, dado o intuito de investigar como esses atores produzem o mundo à sua volta (Flick, 2009a). Para tal foi empreendido um estudo exploratório (Gil, 1991). Essa investida foi baseada no método etnográfico para fazer um relato honesto de todos os dados levantados no decorrer do trabalho de campo e balancear, de um lado, a observação direta, as declarações e interpretações nativas e, de outro, as inferências do pesquisador (Malinowski, 1978). Por este prisma, pouco importa as observações dos atores em geral, mas a observação se voltou para atores específicos e suas singularidades (Whyte, 2005). Ainda, esse estudo etnográfico se amparou na perspectiva do interacionismo simbólico proposto por Blumer (1986), ou seja, para 
sondar como esses atores que plantam a própria maconha atribuem sentido e significado àquilo que pensam e fazem.

A pesquisa de mapeamento etnográfico contou com nove atores entrevistados ao longo de um trabalho de campo que durou cerca de dez meses, sendo seis meses através de redes sociais, como Facebook e Whatsapp, e visitas pontuais a alguns atores para geração de confiança e inserção no campo de pesquisa. Feito isso, durante quatro meses residimos em "Greenville" 1 , uma cidade universitária no interior do Brasil, para interações, observações e realização de entrevistas semiestruturadas, uma vez que nessa cidade foram mapeados cinco atores que plantavam a própria maconha. Através desses cinco atores previamente contatados, fomos levados a mais de vinte atores da mesma rede através da técnica de amostragem em bola de neve (Vinuto, 2014), porém só foi possível entrevistar nove atores, pois atores que haviam se comprometido a participar da investigação desistiram de conceder as entrevistas temendo ser identificadas e, consequentemente, punidas. Esse temor se intensificou, pois, antes do início do período de coleta das informações, uma pessoa que cultivava a própria maconha havia sido autuada pela polícia.

Foram produzidos um trabalho e um diário de campo para levantar e registrar informações para o estudo em questão, onde o trabalho de campo não foi feito através da vivência e observação participante frequente com os atores, mas a partir da busca de interação com eles e, quando possível, realizamos visitas pontuais para a realização de diálogos e entrevistas. Neste caso, o pesquisador praticamente não reside e não se isola com os atores da pesquisa e, quando o faz, é por pouco tempo, mas busca a interação simbólica sempre que possível, a identificação dos valores e as aspirações desses atores (Durham, 1986).

Para mapear essa rede de atores foi utilizada a técnica de amostragem em bola de neve, pois, conforme Vinuto (2014), esse tipo de amostragem é demasiadamente útil para estudar atores difíceis de serem acessados, principalmente quando o estudo trata questões delicadas, privadas e que requer conhecimento das pessoas enredadas umas nas outras através de cadeias de referências não probabilísticas. Nessa perspectiva, foi solicitado aos atores e informantes-chaves, que foram inicialmente contatados, para que indicassem outros possíveis entrevistados e, desta maneira, colaborarem para a construção de uma rede de entrevistados (Fraga \& Silva, 2017).

Foram realizadas entrevistas qualitativas semiestruturadas, ou seja, a forma de aplicação das entrevistas foi mediante um diálogo semiaberto com o entrevistado e um conjunto de perguntas (Flick, 2009b). Foi entrevistado o máximo de pessoas possíveis, totalizando nove pessoas, oito homens e uma mulher. As pessoas tinham entre 20 e 50 anos de idade, todas eram estudantes universitários, 
pertencentes à classe média, habitavam em bairros com boa estrutura urbana e de transporte e residiam em "Greenville". As entrevistas buscaram atingir um critério de saturação satisfatório dos pontos de vistas dos entrevistados, isto é, repetições fartas dos espectros de suas elocuções. Entretanto, esta saturação não chega a ser atingida devido ao número não tão alto de atores que plantam maconha na região em que foi realizado o trabalho de campo e, também, porque muitos atores, como informado anteriormente, desistiram de colaborar ou não responderam à convocação.

Sobre a ética na pesquisa, estabelecemos uma relação com os entrevistados próxima o suficiente para conseguir falar sobre temas delicados e, ao mesmo tempo, buscar evitar gerar falsas expectativas nos entrevistados (Flick, 2009b). Nesse sentido, ficou claro que a relação foi específica da pesquisa, sem dar aos entrevistados a sensação de serem devassados ou de sofrerem abusos por parte dos pesquisadores.

Além disso, foram levados em consideração alguns princípios básicos para uma pesquisa eticamente sólida: $i$ ) o consentimento informado; ii) evita-se enganar os entrevistados; iii) a privacidade dos participantes é respeitada e sua confidencialidade, garantida e mantida; iv) a precisão dos dados e sua interpretação são princípios orientadores, não ocorrendo qualquer omissão ou fraude com a coleta e análise de dados; $v$ ) em relação aos participantes, o respeito à pessoa foi considerado essencial; vi) consideração pelo bem estar dos participantes; vii) tratar a relação de benefícios e ônus para os participantes da pesquisa (Flick, 2009b).

A entrevista em profundidade é uma técnica conveniente na pesquisa social, uma vez que as falas dos atores referem-se a pensamentos, sentimentos, memórias, planos e discussões deles. Nove entrevistas foram feitas nas casas dos atores, mas duas, por conveniência, foram feitas em público na "Universidade de Greenville". Desta maneira, a análise de conteúdo permitiu reconstruir indicadores permeados de cosmovisões, valores, atitudes, opiniões, dentre outros, e compará-los (Bauer \& Gaskell, 2010).

Sobre a análise de conteúdo das entrevistas, buscou-se a plurivocalidade através da polifonia de vozes, então foram enfatizadas as vozes dos atores entrevistados com o intuito de maximizar a representação de ideias e perspectivas e, sendo assim, conferir um aspecto de autoria coletiva (Caldeira, 1988). Os dados, tanto das entrevistas quanto das observações, interações e leituras de teóricas, foram analisados a partir do material levantado no decorrer da pesquisa, de modo que teoria e problema foram responsáveis pela seleção e categorização dos materiais em texto, tanto implícita ou explicitamente, no decorrer do corpus textual. 


\section{Resultados}

Excurso sobre as justificações e os móbeis morais

Nesta seção busca-se fazer uma sociologia dos vocabulários de motivos, ou seja, analisar os motivos que são alocados para orientar o sentido das ações, de modo que um conjunto de formas de falar da ação para que elas possam ser consideradas legítimas (Werneck, 2013). Neste sentido, os móbeis morais, basicamente, perpassam pelos vocábulos que tentam dar legitimidade moral às motivações dos atores entrevistados em relação às práticas de cultivo caseiro da própria maconha que consome. $\mathrm{O}$ primeiro entrevistado, que aqui será chamado de João, relatou:

Vai fazer um ano que comecei a plantar, e colhi poucas plantas. E não faz sentido você comprar, porque você tem dois polos de ilegalidade, e ambos são ilegais, como posse/consumo e comprar. Se você está comprando, você está participando do tráfico, só existe tráfico porque existe usuário e só existe usuário porque existe o tráfico. Então entre ficar nesse tráfico e ficar na outra ilegalidade, que é plantar, e sair dessa ilegalidade que é o tráfico, eu prefiro plantar.

Se considerarmos dois operadores clássicos da accountability social, a justificação e a desculpa, onde no primeiro o ator sabe exatamente o que está fazendo, e no segundo ele diz que fez errado, mas eu não sabia o que estava fazendo e não teve actância efetiva, porque outra coisa/ator é que teve, trata-se de dois dispositivos linguageiros de respostas a julgamentos morais que surgem diante de críticas ou acusações (Werneck, 2013). Nas falas de João percebe-se a justificação de começar a cultivar a própria maconha, objetivando parar de comprar do tráfico ilegal de maconha, pois considera o risco tanto de comprar do tráfico ou plantar em casa seria relativamente o mesmo. Há em sua narrativa um ideário moral constituído em torno de uma representação da imagem do traficante, que é a busca para desvencilhar-se da imagem do traficante, forjando uma diferenciação. Porém, o plantio de João é insuficiente para suprir seu consumo diário, resguardando essa cannabis vista como especial que ele mesmo planta para uso em ocasiões extraordinárias. Apesar dos esforços de jardinagem e de sua construção narrativa em torno do comércio ilegal, ele ainda recorre ao tráfico de rua para suprir seu uso diário de maconha. De outra maneira, o seu constructo moral trabalha na justificação moral de seu ato, reforçando a condenação do tráfico aliando sua narrativa aos preceitos legais que critica.

Ronaldo e Gilberto foram dois atores entrevistados simultaneamente, pois dividiam um sítio juntos e lá plantavam e também dividiam a própria maconha entre eles. Sobre começar a plantar a própria maconha, Gilberto disse: 
Acho que depois de um tempo fumando, você percebe, por causa das experiências e tudo, e morando em um lugar propício, você quer experimentar uma coisa natural, uma coisa que é uma maconha de verdade, não é misturada com nada, não é "prensasa" 2 , não adicionam coisas nela.

Já Ronaldo argumentou:

Eu acho que quando a gente teve o primeiro contato com um "buddie" [uma das formas nativas de chamar a própria maconha plantada] de verdade é que a gente teve interesse de plantar, aí você percebe que é uma coisa pura, uma onda completamente diferente, uma onda mais leve, mais pura, você fica menos chapado e mais feliz, aí pensei: quero ter a curiosidade de plantar isso aí e não precisar comprar no morro ou em favela.

Ronaldo e Gilberto ocultaram durante toda a entrevista que estavam cultivando a própria cannabis. Velho (2008) argumenta que usuários de drogas psicoativas tendem a ocultar o uso para não darem "bandeira", ou seja, não demonstrarem que fizeram uso de psicoativos. Ronaldo e Gilberto tentaram não dar "bandeira" em relação a estar plantando cannabis, portanto tomaram todo cuidado para não ser registrado na gravação da entrevista que eles estavam cultivando a própria maconha. Só com o gravador desligado que eles admitiam a prática de jardinagem. Dias depois, quando fomos convidados para a festa de aniversário de Gilberto, eles disseram que não tinha problemas colocar na pesquisa que eles estavam plantando, pois eles já tinham confiança o suficiente de que não seriam identificados. Ocultar que planta a própria maconha tornou-se comum não somente nessa entrevista, mas em outras. Pode-se presumir que eles se colocam moralmente em jogo com as regras formais e informais, como bem propôs Becker (2009) quando se trata do uso. Não obstante, trata-se de uma estratégia de auto-segurança, no sentido de não se exporem aos riscos de serem incriminados por causa da prática de cultivo.

Começar a plantar também se mostra como algo desencadeado pela experiência de fumar o "verde"3 ${ }^{3}$ pela primeira vez através de relações sociais que estabeleceram em suas redes de sociabilidade, o que é análogo à proposição de Becker (2009) quando propõe que um ator se torna um usuário de maconha. Esses atores são alguns dos poucos, no universo dos nove entrevistados, que conseguem plantar maconha e sustentarem o uso diário do próprio plantio, não recorrendo ao tráfico de rua. Eles também tentaram separar suas imagens da personagem traficante de drogas, e apontaram que a maconha plantada e colhida em casa é algo "puro" e "diferente". Nessa perspectiva, a questão do que denominam como "pureza" da maconha começa aparecer como algo recorrente nas falas, e, embora alguns entrevistados procurassem consumir apenas do "verde", como Ronaldo e Gilberto, esse 
critério de "pureza" não era uma coisa impermeável por estes dois atores. Observou-se no trabalho de campo que algumas vezes estes dois entrevistados fizeram uso da maconha prensada do tráfico de rua com amigos, sem menores problemas, e demonstraram que a barreira colocada por eles para consumir apenas uma maconha "pura" é tênue o suficiente para ser ultrapassada e, portanto, permeável em algumas ocasiões.

O quarto entrevistado, Joaquim, relatou:

E eu comecei a plantar quando eu vim para "Greenville", em 2015, e estava osso [ruim] depender do tráfico, e o mal que isso traz para outras pessoas. Hoje eu não tenho uma produção que me atende totalmente, então eu acabo que tendo que recorrer ao "prensado" para usar diariamente.

Percebe-se que na justificação existe uma tentativa de renegar a qualificação pejorativa de um ato, pois no caso o criticado/acusado considera que a crítica/acusação foi feita de forma injusta e baseada em algum princípio que não corresponde àquele usado por ele para tornar efetiva sua ação (Werneck, 2013). Nas falas de Joaquim evidenciam-se móbeis que o levou a plantar a própria maconha, que perpassa pelo mesmo espectro de não se envolver com o tráfico de drogas, com a figura do traficante, enfim, os mesmos argumentos anteriores, e que não por coincidência também serão os argumentos dos próximos entrevistados. Assim como João, Joaquim não consegue um plantio suficiente para o consumo diário, e ainda recorre ao comércio ilegal para consumir maconha diariamente.

Sobre o motivo de começar a plantar a própria maconha, Antônio alega:

Porque é melhor a plantada, pra quem fuma e se envolve bem. Tem todo esse aspecto ritualístico de você ver a planta crescer e depois você fumar ela, é uma sensação bem melhor do que você ir lá comprar um "prensado". Ontem mesmo tive que fazer um corre [compra] de "prensado", nossa senhora! Eu fui a três bocas diferentes. Maior correria. Isso é ruim. Então você poder plantar e ter o seu ali, colhendo de casa, uma coisa boa, qualidade muito maior do que o "prensado", ter a própria planta é o sonho de quem gosta mesmo de consumir a parada.

As motivações alegadas por Antônio para justificar seu envolvimento com o plantio de cannabis para autoconsumo não se diferencia de outros entrevistados. $\mathrm{Na}$ menção ao plantio para autoconsumo como uma prática similar a um ritual, percebe-se a domesticação mútua que Veríssimo (2017) expõe em sua pesquisa, em que no ato de cultivar a própria maconha, tanto o cultivador domestica a planta quanto a planta o domestica, de modo que a principal "magia" do jardim canábico não seja propriamente a produção da planta, mas também a parte da domesticação do 
jardineiro pela planta. Além disso, a relação ritualística do humano com o inumano, desde o plantio até o consumo, aponta para uma relação diferenciada entre ambos e, portanto, de sentido e significado próprios.

"Agir no social, dessa maneira, passa a ser se deparar com os desafios situacionais e lançar mão competentemente de coisas do mundo para dar conta das ações/situações" (Werneck, 2013, p. 707). Fraga (2012), em pesquisa desenvolvida com trabalhadores rurais envolvidos com plantios extensivos de cannabis, também verificou narrativas dos cultivadores que buscavam diferenciar suas atividades daquelas que classificavam como bandidos, alegando estarem trabalhando e, não, prejudicando alguém, embora reconhecessem como ação ilegal. Como dimensões da agência, a capacidade de decidir por si o curso da ação desenha uma avaliação moral ao tornar efetiva a tomada de um caminho para fixar outra situação no mundo, firmando dispositivos de configuração da agência ou actância, e o cerne passa a ser não o que torna uma ação legítima, mas o que torna uma situação efetiva, capaz de produzir efeitos e consequências, sendo um setting da experiência, da própria vida social, da moral e do que acontece (Werneck, 2013).

Sobre as motivações e justificações de começarem a plantar a própria cannabis, Maria Joana e Ramos, dois atores que também dividem a mesma casa e, consequentemente, a maconha que plantam ilegalmente juntos, relataram o mesmo que os demais entrevistados sobre não se envolverem com o tráfico de drogas, consumir um produto de melhor qualidade e menos insalubre, dentre outros. Também são atores que não conseguem sustentar o uso diário de maconha através do próprio plantio e, por isso, também recorrem ao comércio ilegal para tal. Isso fica evidente na fala de Maria Joana, que expressou:

Plantamos para fumar de vez em quando, porque a gente não tem um cultivo programado para fazer todas as etapas da planta e o tempo todo gerar a "flor", então a gente não consegue fazer isso, igual hoje, a gente tem três vasos, e quando for colher elas serão colhidas ao mesmo tempo, e até ter outras demora um tempo, e a gente acaba fumando do "prensado".

Emanuel é um dos três entrevistados que consegue consumir apenas a maconha cultivada por ele, e sua colocação foi a seguinte:

E esses "prensados", esses não têm controle nenhum, não tem cuidado nenhum, você não sabe o que jogou ali para adubar, você não sabe o que os caras fazem naquele processo, chega um produto em sua mão que você não tem nada, ninguém tem que te dar satisfação nenhuma, muitas vezes você tem de subir em um morro para buscar, se envolver com coisas que transformam a coisa. Eu te mostrei ali o tamanho do espaço que eu uso para cultivar minhas plantas, sabe? O que isso tira aqui no meu quintal? O quê 
isso está oferecendo de risco para a sociedade em volta de mim? Isso não é nada, cara! Não tem nada ali, se têm ali uns vasos com plantas, para mim facilita a vida, já têm uns oito anos que eu não me envolvo com o tráfico de drogas, subir o morro, ou ir ali buscar com o fulano, ligar para o outro ciclano, sabe? Eu tenho aqui na minha casa o processo inteiro.

A agência competente pode ser uma agência moral que adquire a forma de um operador lógico, a competência, e esse operador se distende entre dois sentidos, como dado cognitivo e como forma operativa (Werneck, 2013). Emanuel não adquire maconha há oito anos e, consequentemente, não tem mais contato com o tráfico, colocando-o como o entrevistado que há mais tempo consegue sustentar seu consumo através da própria maconha cultivada. Outros cultivadores que também conseguem se sustentar com suas plantas são Ronaldo e Gilberto.

José, último entrevistado, explanou:

Tendo acesso a algumas leituras e a experiências, o uso vai tomando outro sentindo e acaba levando à ideia do plantar pra quebrar com essa lógica de fomentar o tráfico. Então a ideia de plantar veio unicamente disso, traçando essa coisa do produto de qualidade, e também pra poder, se de fato existir a guerra contra o tráfico, fazer a minha contribuição, ela vai nesse sentido, de não fomentar mais violência.

Seus argumentos não são diferentes dos demais entrevistados e, paradoxalmente, ele também não consegue sustentar o uso diário através de suas plantas e ainda recorre ao comércio ilegal para isso.

A paixão pela vontade inebriante constitui móbeis capazes de contornar a privação de suas causas, mesmo que tais vontades sejam movidas por razões moralmente condenáveis (Magalhães, 1994). Com o passar do tempo, o aprendizado e a aquisição do controle e costume de consumir maconha aos poucos faz com que desapareçam nos consumidores as possíveis resistências iniciais que compunham a associação do uso de maconha às coisas marginais, dependência ou alienação, e o uso passa então a assumir uma conotação habitual de algo prazeroso, pacífico e inócuo (Macrae \& Simões, 2000). O mesmo é observado em relação ao plantio caseiro da própria maconha.

Pode-se perceber que existem várias linguagens de justificação (Werneck, 2013) que constituem os móbeis morais dessa rede de atores. Uma que apareceu em todas as entrevistas foi a ideia de que esses atores queriam consumir uma maconha de melhor qualidade e que não fosse insalubre, como a maconha oriunda do tráfico de drogas, sobretudo a maconha comprimida em prensa e que geralmente vem do Paraguai. Mas a justificação mobilizada que mais chamou atenção é a que perpassou pelos argumentos de não comprar maconha e não financiar a violência proveniente 
do tráfico de drogas. Pode-se perceber em todas as falas que aparece uma coisa em comum, que é tentativa desses atores morais de desvencilhar suas imagens da imagem dos traficantes de drogas. Mas essas falas que mobilizam justificações morais alinham-se às práticas e a agentes que rotulam as suas ações de cultivo e jardinagem.

Sabe-se que no Brasil o tráfico de drogas ilícitas não pode ser tomado como uma prática homogênea, pois existem diferentes tráficos, onde dois exemplos contrastantes são o "tráfico" nos bairros de classe média, como demonstram Grillo (2008), Daudelin e Ratton (2017), em que alguns até têm entregas delivery de drogas, e o outro extremo, o tráfico comum de rua, sendo deste último o exemplo mais comum aqueles das favelas da cidade do Rio de Janeiro, onde os traficantes geralmente andam armados e são considerados por diversas narrativas que constroem o personagem do traficante como inimigo público, conforme proposto por Foucault (2015). É da imagem desse traficante armado, sobretudo da imagem daqueles das favelas do Rio de Janeiro, que os "growers" tentam desvencilhar suas imagens, pois aparentemente eles não possuem problemas morais e simbólicos com o tráfico delivery de classe média, inclusive alguns dos atores entrevistados ainda recorrem à este tráfico para suprirem seus consumos diários.

Essa tentativa dos usuários-cultivadores de separarem suas imagens da do traficante armado pode ser análogo a uma tentativa de limpeza simbólica e moral. A limpeza simbólica, conforme sugerido por Machado (2008), seria uma tentativa de separação que os moradores das favelas tentam fazer de si mesmos para com os traficantes, uma vez que as desaprovações pelos primeiros em relação às práticas dos segundos se constituem como fronteiras morais. Embora nenhum dos entrevistados dessa pesquisa fosse morador de favela, pode-se considerar que aparece uma relação de limpeza simbólica e moral nas narrativas e justificações dos entrevistados, uma vez que estes usuários-cultivadores de maconha sempre buscam separar suas imagens da dos traficantes, pois compram o ideário moral comum de que o traficante é de fato um dos maiores inimigos da sociedade brasileira.

Pode-se perceber que existe uma contradição entre narrativa e prática por alguns usuários-cultivadores, e a maconha plantada de seis atores fica guardada para uso em ocasiões extraordinárias. Ademais, os três usuários-cultivadores que conseguem o sustento próprio, apesar de plantarem não com o intuito comercial, dependendo da ocasião, consomem essa cannabis juntos com conhecidos, ou mesmo doam ou negociam para amigos mais próximos, e as três coisas são consideradas tráfico de drogas pela legislação brasileira (Brasil, 2006). Isso aparece como algo paradoxal, pois ao mesmo tempo em que tentam propor uma limpeza simbólica e moral em relação ao traficante de drogas, seis atores ainda recorrem ao tráfico de drogas para poderem usar maconha diariamente ou, ainda, pode-se dizer todos 
praticam atos que podem ser consideradas tráfico de drogas pela legislação brasileira.

Essa ambivalência ilustra as reflexões sobre os limites e os conflitos das redes morais. No terreno das moralidades o conflito é dogmático (Magalhães, 1994). De acordo Telles e Hirata (2007), pode-se considerar tênue o limiar que estabelece as fronteiras porosas entre o que é considerado moral-imoral, de modo que o trânsito entre essas fronteiras porosas pode ser considerado comum. Fraga (2012), também, percebeu essa delgada fronteira entre trabalhadores rurais que vivenciam as experiências de laborar tanto para os plantios lícitos quanto para os ilícitos em momentos de suas vidas e construírem justificações morais para esse movimento. Nessa perspectiva, os conflitos morais podem ser positivos quando são fontes de transições morais. Ao mesmo em tempo que os conflitos morais preservam os limites internos e externos das redes morais, esses limites são tênues e permeáveis, o que permite o estabelecimento de unidades conflituosas tanto homogêneas quanto heterogêneas, assim como endógenas ou exógenas.

A partir do espectro das falas das entrevistas em profundidade, conjetura-se que começar a plantar a própria maconha é uma prática que se estabelece a partir de ações, interações e associações configuradas a partir de suas redes morais de amigos. O gosto de fumar maconha, como já foi percebido por Becker (2009), é fruto de interações entre atores sociais. Nessa perspectiva, os gostos de plantar a própria maconha, destes nove atores entrevistados, são firmados através das conexões morais específicas assentadas em suas redes de interações. Essas associações morais estabelecidas nessas redes de interações agregam moralmente atores que adquiriram o gosto de fumar e, posterirormente, de plantar a própria maconha, alterando a relação entre os atores e a planta, que inclusive é diferente de quem apenas fuma e não planta, configurando um novo sentido moral.

\section{Relações de solidariedade, reciprocidade e cooperação}

Como uma fonte de vida moral sui generis, as associações também configuram relações de solidariedade, pois através delas se configuram no seio da sociedade geral sentimentos, interesses e ideias comuns para levar em conjunto uma vida moral (Durkheim, 1983a). Nessa perspectiva, considera-se que dessas vidas morais que se desprendem pelas sociedades afora redes de interesses, ideias e sentimentos que fazem o apego por alguma coisa ultrapassar o âmbito individual para o social, criando entre duas ou mais pessoas um sentimento de solidariedade e suscitando sociedades de amigos. Às suas diferentes maneiras, essas redes morais se organizam, dado que este é um elemento normal da vida comum que os atores envolvidos estabelecem entre si. Por este prisma, nessa seção será analisado como se configuram as 
relações de solidariedade, reciprocidade e cooperação nas redes morais de usuários-cultivadores de cannabis.

João planta sua maconha dentro do guarda-roupa com luzes artificiais, em um sistema chamado "indoor", e em dado momento da entrevista relatou:

Quando chega num estado vegetativo eu levo para o "outdoor" [fora de casa], mas sempre" "semi-in" e "semi-out", está ligado? Aí no caso dos "outdoors" são terceiros que fazem a fase de florescência para mim, então acaba que meu ganho da planta é sempre menor que eu tivesse se eu tivesse colocado para florir aqui no guarda-roupa [indoor], eu sempre divido minhas plantas pela metade, eu nunca colhi uma planta inteira para mim. Às vezes uma planta dá 30 gramas e eu só fico com 15 dela, porque a metade fica com o cara que floriu para mim, porque ele também corre os mesmos riscos, só que ele tem um lugar para florir.

No âmbito das relações de solidariedade, reciprocidade e cooperação, nas palavras de João, foi possível identificar que existe um sistema meeiro diferente do identificado por Fraga (2006), em que o agricultor plantava e o patrão vendia, e depois dividiam o dinheiro entre eles. Entre João e outros atores se configura um sistema meeiro de divisão entre esses usuários-cultivadores. Quando João foi questionado se ele conhece mais pessoas que plantam e como se relaciona com elas, ele respondeu:

É por isso que a gente conhece pessoas e "growers", se a gente não se conhecesse e não se identificasse, a gente não aumentaria a rede, e a gente não troca necessariamente só informação, mas às vezes trocamos plantas, porque muitos têm que começar, têm muitas pessoas querendo começar, e eu acho que essas pessoas precisam de um norte se elas estão levando a mesma conduta que estou levando.

Ao tratar da reciprocidade, Whyte (2005) argumenta que as relações pessoais e a reciprocidade configuram muitas interações, assim como trocas recíprocas a partir dos diferentes padrões de atividades e lógicas de pertencimento em que certos atores se envolvem. João expõe que quando se identifica com outros atores cultivadores, ele sempre se dispõe a ajudá-los a começar, e sobre as relações de solidariedade, reciprocidade e cooperação, ele relata que trocam não apenas informações e conhecimento, mas às vezes trocam plantas, a maconha pronta para consumir e outras coisas. Além disso, têm as relações de meeiros que ele estabelece com outros atores cultivadores.

Sobre as relações com outras pessoas que também plantam a própria maconha para uso social, Ronaldo relatou: "Conheço! Conheço alguns amigos e a gente troca informações de como fazer, manipular melhor a planta. Com certeza o 
conhecimento tem de ser passado". E Gilberto complementou: "A gente troca informações para poder plantar e ter um rendimento um pouco melhor". Ronaldo e Gilberto mostraram receio em expor os detalhes de suas relações com outros atores que também cultivam a própria maconha, mas relataram que conhecem e se relacionam com eles, e que cooperam entre si através de troca de informações de como manipular melhor a planta.

Joaquim relatou:

A gente troca informações, uma coisa que dá errado com um e dá certo com outro, a gente cruza essas informações de utilização, mesmo do "grow indoor", tempo de luz, ventilação, troca de muda de plantas etc. Então a gente faz um sistema bem coletivo de troca de informações, sementes, mudas para poder ajudar a quem se disponha a correr o mesmo risco, poder colher e todo mundo poder fumar da flor de verdade. Porque a gente pensa: Eu estou fazendo isso. E o outro: 'Eu também estou fazendo isso'. Então nós estamos juntos! E quando vi têm cinco ou seis que fazem, às vezes moram juntos, às vezes não. Então começa a meio que fazer uma sociedade ali de pessoas com o mesmo fim, não é? Todo mundo correndo o mesmo risco, mas com o mesmo intuito de sair dessa ideia do tráfico e poder ter esse sustento próprio através do próprio plantio.

Joaquim expõe que eles trocam informações sobre coisas que dão errado, cruzam informações diversas e trocam plantas e "camarão" (outra forma como a maconha plantada em casa também é chamada). Interessante notar que o risco que correm pela prática ilegal do plantio, nesse sentido, começa a aparecer como um sentimento que pode ser visto como uma das fontes de agregação dessa rede moral e, logo, de associação moral e cooperação (Durkheim, 1983a). Assim como João, Joaquim deixa claro que sempre se dispõe a ajudar outras pessoas que se disponham a correr o mesmo risco.

Antônio expôs:

Sim, nós trocamos informações. Aqui em Greenville tem a galera que planta também, mas eu acho que não ficam falando por aí que plantam. Mas uma ou outra pessoa que eu sei que planta, nós compartilhamos informações. Mas é uma coisa bem restrita ainda, porque ninguém fica falando que planta e tal. Aí você vê como é que a ilegalidade reflete nisso, e se não fosse ilegal todo mundo ia estar falando, compartilhando informações, compartilhando espécies de plantas, variedades etc.

Antônio também conhece mais pessoas que moram em Greenville e que plantam a própria maconha, e com esses conhecidos ele troca informações quando necessário. Mas essa troca de informações, genéticas de plantas e outras coisas ocorrem 
apenas com uma rede restrita de atores, configurando-se como um grupo reservado, caracterizado pela confiança mútua e pelo compartilhamento de princípios comuns. Para Antônio a ilegalidade é o maior empecilho para estas relações de cooperação e reciprocidade, acredita que a ilegalidade é fator decisivo para restringir a capacidade de expansão da rede. Nota-se uma configuração de tipo voluntarista, ou seja, uma moral associativa que estabelece laços de participação moral eletiva entre atores sociais (Paugam, 2018). Neste sentido, usuários-cultivadores de cannabis configuram associações em redes morais e relações de assistência recíproca entre eles para satisfazerem seus sentimentos e interesses para com a planta.

Na entrevista realizada simultaneamente com Ramos e Maria Joana, esta última foi a primeira a se pronunciar, e ela relatou:

Eu costumo trocar informaç̃es, até mesmo porque eu não tenho muito conhecimento sobre plantio, então eu pergunto mais a um pessoal que eu conheço, principalmente aos que têm mais tempo que plantam, qualquer coisa que acontece a gente sai perguntando quem tem conhecimento a mais pra gente se orientar.

Após Maria Joana, Ramos complementou:

É isso, troca de experiências e espécies, genética. Na época que eu morava em uma chácara, a gente tinha o sistema "indoor" lá, dava para utilizar bastante os clones de plantas, e aí rolava bastante troca, às vezes você vai e troca com outras pessoas os clones, ou em sementes mesmo. É legal ver que essa questão não é só com a gente, mas a gente vê que isso acontece bastante, porque quando eu estava na Holanda eu tinha experimentado uma genética lá que eu acho muito boa, que chama Hawaiian Snow, é uma genética muito boa e não tinha dela aqui na época que eu plantava com esse pessoal na chácara, e eu voltei para cá e aí já tinha, e eu fumei com uma pessoa, deu um tempo e todo mundo tinha na cidade uma planta que não tinha. Isso acontece porque uma pessoa planta, a outra vai e clona, e passa para a outra, que passa para a outra, e quando você vai ver já tem uma genética rodando na cidade toda.

Atores em relações comuns, que estão fazendo coisas juntos, têm de coordenar suas ações ao perceber que algo está errado e que tem mudar, expressando o descontentamento desempenhando uma ação conjunta (Boltanski \& Thévenot, 1999). Sendo assim, Maria Joana descreve firmar relações de reciprocidade e cooperação com outros atores morais que também plantam a própria maconha. Ramos reafirma as relações de solidariedade, reciprocidade e cooperação que perpassam pelos interesses mútuos de plantar a própria maconha. Então, trocar informações não é a única prática, mas também genética de plantas e outras coisas relativas ao cultivo da própria maconha. 


\section{Emanuel argumentou:}

Sim, sim! Eu acho que hoje em dia isso se popularizou bem, existem muitas pessoas fazendo isso, muito mais do que na época que eu comecei, e é legal hoje em dia, porque as pessoas trocam informações, trocam genéticas de plantas, trocam as experiências e tal. Está muito mais fácil hoje em dia para ter acesso a esse tipo de coisa, não é? Se a pessoa quiser começar hoje em dia, ela sempre tem um amigo aí que já conhece, faz ou que já fez, então hoje em dia está bem mais fácil.

Na sua exposição também aparecem as relações solidárias através das trocas de informações, genética de plantas e outras experiências de cultivo.

A entrevista com José foi a mais tensa, pois quando começamos a gravar a entrevista, em menos de dois minutos de gravação, ele começou a gaguejar e não conseguiu responder a primeira questão, praticamente travou. José disse: "Cara, que medo de gravar essa entrevista e a polícia vir aqui em casa por causa disso". Mas depois de conversarmos e inclusive nós dizermos que ele não precisava participar da entrevista, ele se acalmou e concedeu seu ponto de vista. Sobre suas relações com outras pessoas que também plantam, José relatou:

Cara, eu conheço vários amigos íntimos, eu tenho um ciclo de amigos e tal, que produzem também. E a gente troca algumas informações vez ou outra, e de repente um fala produziu um que tá bonito, me dá um "green" ali pra eu fumar. A relação é troca de informações, de "camarões", e é isso, tipo, alguns são amigos mais íntimos, mas eu também sei que têm outras pessoas.

Através dessas exposições foi possível observar, mapear e compreender que as relações de solidariedade, cooperação e reciprocidade são construídas em espaços e interações presentes nas redes morais configuradas face a face. Existem relações de reciprocidade e cooperação que formam relações de solidariedade entre esses atores morais para ajudar uns aos outros, mas principalmente os iniciantes e, nessa perspectiva, oferecer uma possível direção ou caminho para quem se dispõe a iniciar nessa mesma conduta considerada ilegal e imoral. Sendo assim, estes atores formam relações solidárias e suscitam sociedades de amigos através de suas redes morais na disposição de ajudar quem se coloca a correr também o risco de plantar a própria maconha.

\section{Conclusão}

O plantio caseiro da própria maconha se apresentou, nessa pesquisa, como uma fonte de relações morais sui generis. Nas redes morais firmadas por esses atores 
acontece a passagem do apego individual para o social pela prática de plantar a própria maconha. Nessa perspectiva, o sentido atribuído a essa prática é imputado pelo comportamento de outros atores que plantam a própria erva. Plantar a própria maconha para o uso social recreativo também se apresentou como um sentimento moral de libertação em relação às repressões formais e informais que esses atores sofrem, e isto faz com que eles estabeleçam relações de solidariedade, cooperação e reciprocidade de interesses e sentimentos, pois possuem ideias e sentimentos comuns que configuram uma moralidade contextualizada no decurso de suas associações em redes.

Os móbeis morais e as relações de sociabilidade dessa rede de atores podem ser os fundamentos para essas outras relações sociais que aparecem aqui, ou seja, das relações de solidariedade, reciprocidade e cooperação, visto que todos entrevistados trocam conhecimentos, experiências e informações sobre como lidar com as plantas, inclusive experiências que deram errado. Além disso, em "Greenville" esses atores morais trocam também sementes, mudas, clones, adubos, genéticas de plantas e até mesmo a substância pronta para consumo.

Esses atores consideram a maconha uma planta normal como qualquer outra, e como se trata de uma prática inócua pra eles, firmam uma moralidade específica ao plantar a própria maconha. Esses atores entendem que o conhecimento sobre o plantio da própria cannabis deve ser passado adiante e compartilhado com outros atores que têm os mesmos interesses, sentimentos e ideias tenham um norte na prática. Portanto, quando esses atores conhecem outros atores que também cultivam a própria maconha e se identificam, eles se dispõem a se ajudarem na prática de plantar a própria maconha para o uso próprio.

Limitações desse trabalho referem-se a sua realização em apenas em uma cidade, o trabalho de campo interacional ter sido reduzido e o número total de entrevistados não atingir um grau satisfatório de saturação. Quiçá seria interessante que fossem feitas outras pesquisas sobre o mesmo tema em outras cidades do Brasil, ou até mesmo de outros países, tanto para entender melhor a diversidade das práticas do cultivo caseiro da própria maconha quanto das relações morais que a permeiam. Desta maneira, tais pesquisas seriam deveras interessantes para trazer mais reflexões sobre as lacunas teóricas e metodológicas dessa pesquisa.

\section{Notas}

Os autores escrevem segundo o novo acordo ortográfico por razões formais de uniformidade linguística. 
Todos os nomes dos atores e de lugares serão nomes fictícios para tratar de lugares e pessoas reais e, dessa forma, resguardar o sigilo e anonimato das identidades dos atores que participaram direta ou indiretamente dessa pesquisa.

2 "Prensado" é como os nativos chamam a modalidade maconha comprimida em prensa, que geralmente vem do Paraguai e é comercializada pelo tráfico de rua.

3 Outro modo como a cannabis plantada em casa é chamada, também pode ser chamada de "green", "camarão" ou "buddie".

\section{Referências}

Alvarez, M., Fraga, P., \& Campos, M. (2017). Apresentação: Perspectivas atuais sobre políticas, produção, comércio e uso de drogas. Tempo Social, 29(2), 1-14. doi: 10.11606/0103-2070.ts.2017.133303.

Bauer, M., \& Gaskell, G. (2010). Pesquisa qualitativa com texto, imagem e som: Um manual prático. Petrópolis: Vozes.

Becker, H. (2009). Outsiders: Estudos de sociologia do desvio. Rio de Janeiro: Zahar.

Bergeron, H. (2012). Sociologia da droga. Aparecida: Ideias \& Letras.

Blumer, H. (1986). Symbolic interactionism: Perspective and method. California: University of California Press.

Boltanski, L., \& Thévenot, L. (1999). The sociology of critical capacity. European Journal of Social Theory, 2(3), 359-377. doi: 10.1177/136843199002003010.

Caldeira, T. (1988). A presença do autor e a pós-modernidade na antropologia. Novos Estudos, (21), 133-157.

Castro, M. (2019). Redes morais: Um estudo exploratório sobre a solidariedade inerente ao cultivo caseiro de maconha para o uso social recreativo (Dissertação de mestrado, Universidade Federal de Juiz de Fora, Brasil).

Daudelin, J., \& Ratton, J. L. (2017). Mercados de drogas, guerra e paz no Recife. Tempo Social, 29(2), 115-133. doi: 10.11606/0103-2070.ts.2017.125670

Durham, E. (1986). A pesquisa antropológica com populações urbanas: Problemas e perspectivas. In R. Cardoso (Org.), A aventura antropológica (pp. 17-34). Rio de Janeiro: Paz e Terra.

Durkheim, E. (1983a). Da divisão do trabalho social. In J. A. Giannotti (Org.), Coleção Os Pensadores, (pp. 1-70). São Paulo: Abril Cultural.

Durkheim, E. (1983b). Lições de Sociologia: A moral, o direito e o Estado. São Paulo: Edusp.

Flick, U. (2009a). Desenho da pesquisa qualitativa. In U. Flick (Org.), Coleção pesquisa qualitativa (Vol. 1, pp. 7-148). Porto Alegre: Bookman.

Flick, U. (2009b). Qualidade na pesquisa qualitativa. In U. Flick (Org.), Coleção pesquisa qualitativa (Vol. 5, pp. 7-196). Porto Alegre: Bookman.

Foucault, M. (2015). A sociedade punitiva: Curso no Collège de France (1972-1973). São Paulo: Martins Fontes.

Fraga, P. C. P. (2006). Plantios ilícitos no Brasil: Notas sobre a violência e o cultivo de cannabis no polígono da maconha. Cadernos de Ciências Humanas-Especiaria, 9(15), 95-118. 
Fraga, P. C. P. (2012). Les actions d'éradication des plantations considérées illicites en Amérique Latine et au Brésil. Déviance et Société, 36(2), 115-135.

Fraga, P. C. P. (2019). A economia do plantio extensivo de cannabis no Brasil e as estratégias de repressão. In P. C. P. Fraga \& M. C. Carvalho (Orgs.), Drogas e sociedade: Estudos comparados Brasil e Portugal (pp. 140-154). Rio de Janeiro: Letra Capital.

Fraga, P. C. P., \& Silva, J. (2017). A participação feminina em mercados ilícitos de drogas no Vale do São Francisco, no Nordeste brasileiro. Tempo Social, 29(2), 135-157. doi: 10.11606/0103-2070.ts.2017.128528.

Gil, A. (1991). Como elaborar projetos de pesquisa. São Paulo: Atlas.

Goffman, E. (1970). Estigma: La identidad deteriorada. Buenos Aires: Amorrortu.

Grillo, C. (2008), O morro e a pista: Um estudo comparado de dinâmicas do comércio ilegal de drogas. Dilemas - Revista de Estudos de Conflito e Controle Social, 1(1), 127-148.

Latour, B. (2012). Reagregando o social: Uma introdução à teoria ator-rede. Salvador: EdUFBA.

Lei $\mathrm{n}^{\circ} 11.343$ de 23 de agosto de 2006. Disponível em http://www.planalto.gov.br/ccivil_03/_ato2004-2006/2006/lei/111343.htm.

Machado, L. (2008). Vida sob cerco: Violência e rotina nas favelas do Rio de Janeiro. Rio de Janeiro: Nova Fronteira.

Macrae, E., \& Simões, J. (2000). Rodas de fumo: O uso da maconha entre camadas médias. Salvador: EdUFBA.

Magalhães, R. (1994). Crítica da razão ébria: Reflexões sobre drogas e a ação imoral. São Paulo: Annablume.

Malinowski, B. (1978). Argonautas do Pacífico Ocidental. In A. Carr, L. A. C. Mendonça \& E. R. D. Coleção Os Pensadores (pp. 17-28). São Paulo: Abril Cultural.

Misse, M. (2010). Crime, sujeito e sujeição criminal: Aspectos de uma contribuição analítica sobre a categoria bandido. Lua Nova, (79), 15-38. doi: 10.1590/S0102-64452010000100003

Paugam, S. (2018). Le lien social: Que sais-je?. Paris: Presses Universitaires de France. Simmel, G. (1983). A natureza sociológica do conflito. In E. M. Filho (Org.), Simmel (pp. 122-134). São Paulo: Ática.

Telles, V., \& Hirata, D. (2007). Cidade e práticas urbanas: Nas fronteiras incertas entre o ilegal, o informal e o ilícito. Estudos avançados, 21(61), 173-191. doi: 10.1590/S0103-40142007000300012

Velho, G. (Ed.) (1981). Duas categorias de acusação na cultura brasileira contemporânea. In Individualismo e cultura: Notas para uma antropologia da sociedade contemporânea (pp. 55-64). Rio de Janeiro: Zahar.

Velho, G. (2008). Nobres E anjos: Um estudo sobre tóxicos e hierarquia. Rio de Janeiro: Editora FGV.

Veríssimo, M. (2017). Maconheiros, fumons e growers: Um estudo comparativo dos consumos e cultivos caseiros de canábis no Rio de Janeiro e em Buenos Aires. Rio de Janeiro: Autografia. 
Vinuto, J. (2014). A amostragem em bola de neve na pesquisa qualitativa: Um debate em aberto. Temáticas, 22(44), 201-218. doi: 10.20396/temáticas.v22i44.10977

Werneck, A. (2013). Sociologia da moral como sociologia da agência. RBSE-Revista Brasileira de Sociologia da Emoção, 12(36), 704-718.

Whyte, W. (2005). Sociedade de esquina. Rio de Janeiro: Zahar.

Data de submissão: 11/07/2020 | Data de aceitação: 15/01/2021

(c) $\frac{(1)}{\mathrm{a}}$ 